hepatic necrosis treated consecutively according to this regimen at the Centre of Internal Medicine, University of Marburg, survived, and complete functional recovery was achieved.

It is concluded that the effective control of coagulation disturbances in fulminant hepatic failure may improve the prognosis. The rapid and sustained replacement treatment may prevent secondary damage of hepatic function as a result of thrombotic occlusion of the microcirculation affecting the regenerative capacity of hepatocytes. The nearly normal liver biopsy in our patient seems to confirm the efficacy of the treatment.

It must be stressed that only patients treated early in the course of the disease may benefit from replacement treatment; at a certain stage damage of the liver and of other organs as well as the associated coagulation disturbances may become irreversible.

\section{References}

I Marks MI, Mauer SM, Goldman H. Exchange transfusion in the treatment of hepatic coma. J Pediatr 1969;75:418-30.

2 Rake MO, Flute PT, Shilkin KB, Lewis ML, Winch J, Williams R. Early and intensive therapy of intravascular coagulation in acute liver failure. Lancet 1971;ii:1215-8.

${ }^{3}$ Egbring R, Klingemann HG, Heimburger N, et al. Antithrombin III substitution in acute hepatic failure duc to $\mathrm{CCl}_{4}$ intoxication. Thromb Haemost 1981:46:373

+ Vogel G, Bottermann P, Kuhlencordt M. et al. Antithrombin III (AT III) in der Bchandlung von Gerinnungsstörungen beim akuten Leberversagen. Verh Dtsch Ges Inn Med 1979;85: 477-80.

5 Zacarias JS, Brinck P. Huidobro JG. Exchange transfusion in the treatment of hepatic coma. J Pediatr 1967;71:660-4.

' Redecker AG, Yamahiro HS. Controlled trial of exchangetransfusion therapy in fulminant hepatitis. Lancet 1973;i:3-6.

Correspondence to Dr R Burghard, Philipps-University of Marburg. Deutschhausstrasse 12, 3550 Marburg, Germany.

Received 13 September 1984

\title{
Ultrasound monitoring of diaphragm activity in bilateral diaphragmatic paralysis
}

\author{
R AMBLER, S GRUENEWALD, AND E JOHN \\ Departments of Paediatrics, Nuclear Medicine, and Ultrasound, Westmead Centre, Australia
}

SUMMARY Recovery of diaphragm activity after bilateral diaphragmatic paralysis was monitored in a term infant using a mechanical sector scanner fitted with a $5 \mathrm{MHz}$ transducer. The ratio of diaphragmatic excursion during spontaneous breathing and ventilator assistance was used as an objective measure for comparison of diaphragmatic activity during recovery. Ultrasound assessment of diaphragm contraction may be used to study progress in diaphragmatic paralysis.

Bilateral diaphragmatic paralysis secondary to birth trauma is a rare occurrence ${ }^{1}$ and most of these babies require ventilatory assistance soon after birth. ${ }^{2}$ Assessment of diaphragmatic recovery clinically or by fluoroscopy becomes difficult once ventilatory assistance has begun. We describe an infant with bilateral diaphragmatic paralysis whose recovery was monitored ultrasonically.

\section{Case report}

A boy weighing $2650 \mathrm{~g}$ was born at term to a 25 year old mother after an uneventful pregnancy and the spontaneous onset of labour. Fetal bradycardia was noted during the second stage of labour and delivery was expedited using Keilland's forceps. Apgar scores were 3 and 4 at one and five minutes respectively. He was intubated at one minute and ventilated with $100 \%$ oxygen. Soon after ventilation began his $\mathrm{pH}$ was 7.04 with a base deficit of 19 $\mathrm{mmol} / \mathrm{l}$. On examination, the infant was hypotonic with no spontaneous movements below the neck. Spontaneous movement of the legs was seen on day 2 and this gradually extended cranially, partial recovery of the deltoid having occurred by day 7 . Inadequate, jerky, inspiratory efforts were first seen on day 12. Diaphragmatic activity was studied on several occasions using real time ultrasound.

Ultrasound images of the right hemidiaphragm were obtained using a mechanical sector scanner fitted with a $5 \mathrm{MHz}$ transducer (Honeywell Ultraimager). The transducer was placed below the right costal margin, and with the liver providing an acoustic window, saggital views were obtained of the posterior portion of the diaphragm until maximum diaphragmatic excursion was observed (Fig. 1). The transducer was held in this position and the movement of the right hemidiaphragm was recorded as an $M$ mode tracing during intermittent positive pressure ventilation and spontaneous breathing. A positive end expiratory pressure of $5 \mathrm{~cm}$ was provided at 


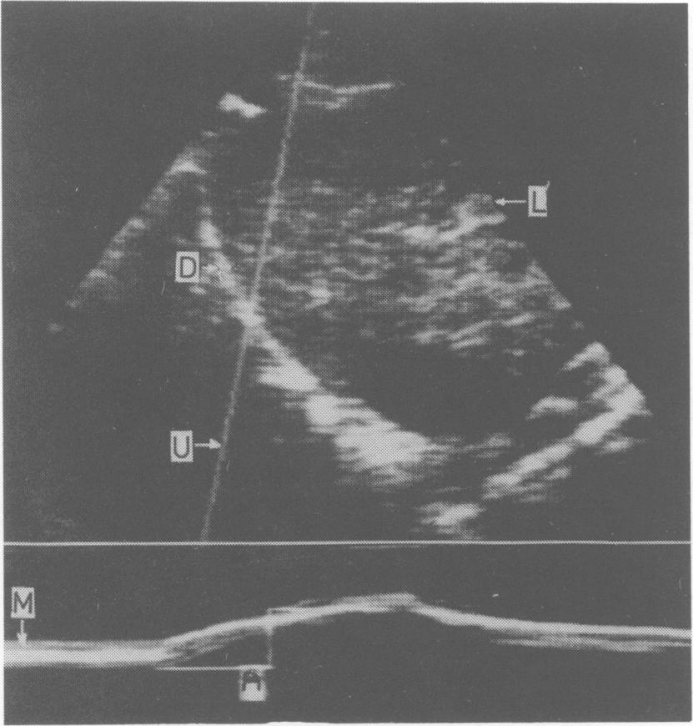

Fig. 1 Right sagittal subcostal view of the liver and diaphragm.

$L=$ liver, $D=$ diaphragm, $u=$ position of ultrasonic beam for $M$ mode tracing, $\mathbf{M}=\mathbf{M}$ mode tracing, $\mathbf{A}=$ excursion of diaphragm. all times. The ratios of diaphragmatic excursion during spontaneous breathing and ventilatory assistance were calculated. The pattern and length of spontaneous diaphragmatic movement were noted on each occasion.

The infant was studied every two weeks during the first two months of life and less frequently thereafter. During the first two months of study the ratio varied between 0.3 and 0.4 ; this was associated with irregular and brief spontaneous diaphragmatic movements (Fig. 2) and inadequate pulmonary gas exchange. The ratio increased gradually during the next few weeks to $0 \cdot 5$, but there was no improvement in the rhythm or duration of diaphragmatic movement. At the age of 6 months, five months after beginning the study, the diaphragmatic excursion during spontaneous breathing was irregular but similar in amplitude and duration to that seen during intermittent positive pressure ventilation (Fig. 3). At this stage the infant was able to maintain adequate gas exchange for up to two hours of spontaneous breathing. By 8 months of age, the amplitude had increased further and diaphragmatic movements were smoother and more regular, so that assisted ventilation was only required during sleep. Neurodevelopmental assessment showed a

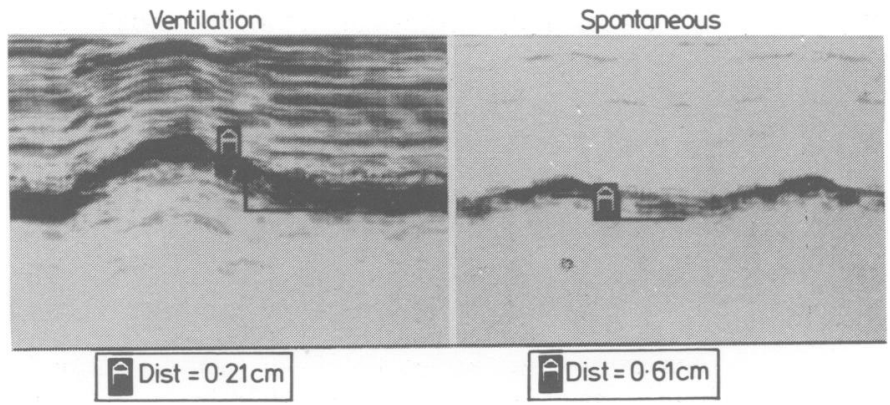

Fig. 2 Comparison of $M$ mode ultrasonic tracings while patient was on positive pressure ventilation (Ventilation) and breathing spontaneously (Spontaneous).

$A=$ excursion of diaphragm.

Fig. 3 Comparison of $M$ mode ultrasonic tracings during recovery.

$A=$ excursion of diaphragm.

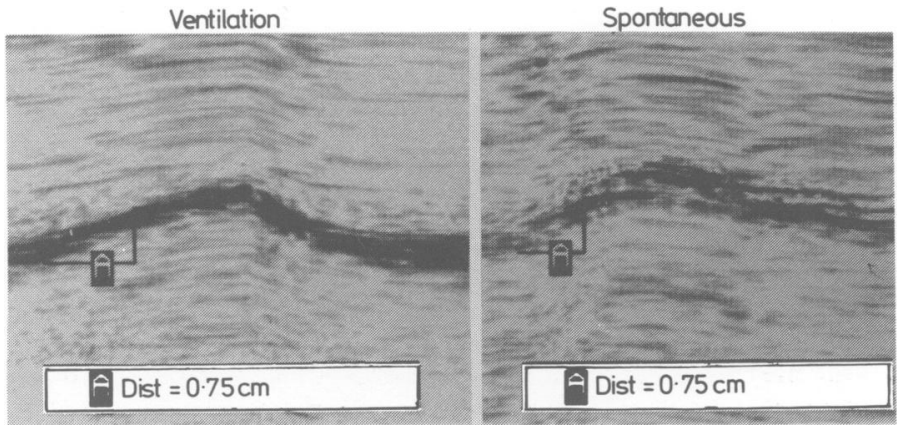


hypotonic infant with greater involvement of the right side and a rounded back and shoulder while sitting. His developmental age was that of a 6 month old infant.

\section{Comment}

The diaphragm is important in maintaining minute ventilation in the human infant, ${ }^{1}$ and hence bilateral diaphragmatic paralysis requires active intervention if gas exchange is to be maintained. In the series report by Aldrich et al, ${ }^{2}$ four or five infants who showed improvement in diaphragmatic contraction with time, survived, suggesting that the return of diaphragmatic function was a major factor influencing survival. Serial assessment of diaphragmatic function would, therefore, aid in predicting outcome.

Fluoroscopy is the most common method of showing diaphragmatic paralysis and assessing recovery, either spontaneously or after electrophrenic pacing. ${ }^{3}$ The major disadvantages of this technique are the radiation burden to the infant and the absence of a permanent record of diaphragmatic excursion. Both of these drawbacks may be overcome by the use of ultrasound to assess diaphragmatic movement. ${ }^{4}$ Cases of eventration and paralysis have been correctly diagnosed ${ }^{5}$ by the use of $B$ and $M$ mode ultrasound, and real time ultrasound is potentially more useful especially in infants.

Real time ultrasound is commonly used in neonatal nurseries to aid diagnosis and management, and most regional centres have easy access to these facilities. It is suggested that this technique may be profitably applied to the sequential monitoring of infants with diaphragmatic paralysis.

\section{References}

1 Greene H, L'Heureux P, Hunt CE. Paralysis of the diaphragm. Am J Dis Child 1975;129:1402-5.

2 Aldrich TK, Herman JH, Rochester DF. Bilateral diaphragmatic paralysis in the newborn infant. J Pediatr 1980;97:988-90.

${ }^{3}$ Yasuda R, Nishioka T, Fukumasu H, Yokota Y. Bilateral phrenic nerve palsy in the newborn infant. A case report J Pediatr 1976;89:986-7.

${ }^{4}$ Haber K, Asher M, Freimanis AK. Echographic evaluation of diaphragmatic motion in intra-abdominal diseases. Radiology 1975;114:141-4

${ }^{5}$ Haller JO, Schneider M, Kassner EG, Friedman AP, Waldroup $\mathrm{LD}$. Sonographic evaluation of the chest in infants and children. AJR 1980;134:1019-27.

Correspondence to $\mathrm{Dr}$ E John, Department of Paediatrics, Westmead Centre, Westmead, N.S.W. 2145, Australia.

Received 10 July 1984 